\title{
Carbon sequestration and the limits of regulation: a UK perspective \\ Mark Stallworthy
}

Swansea University

\section{Introduction}

Considerable political capital is invested in developed economies in the idea of carbon $C_{c a p t u r e}$ and storage (CCS), with a heavy weight of expectation upon eventual deployment. ${ }^{1}$ The UK government describes it as 'key if the UK is to achieve our climate change targets whilst maintaining a vibrant, competitive economy'. ${ }^{2}$ The purpose behind CCS is to mitigate impacts from burning fossil fuel energy sources by diverting carbon emissions away from atmospheric release. Complex technology applies, but simply put, CCS involves capture (by chemical and other means) of carbon dioxide $\left(\mathrm{CO}_{2}\right)$ from major point source installations, ${ }^{3}$ to be compressed and transported, generally via pipelines, to designated sites (principally in depleted oil and gas fields, or saline aquifers), for permanent storage by injection into deep geological formations, below ground or under the seabed. ${ }^{4}$ Thus is held out the enticing promise of at last a significant technological response to climate change; one which yet remains unproven as a composite process to a large scale. Yet if not as controversial as are certain other proposed geo-engineering solutions, ${ }^{5}$ CCS may prove a poisoned chalice, insofar as political expectations for it can slow development of alternative energy strategies. By contrast with more developed areas of climate change law, and arguably reflecting the still inchoate existence of the physical process itself, a body of

1 See eg IEA, Carbon Capture and Storage: Model Regulatory Framework (OECD/IEA 2010) 1.1.1.

2 Department of Energy and Climate Change (DECC), CCS Roadmap: Supporting Deployment of Carbon Capture and Storage in the UK (April 2012) 2.5 <www.gov.uk/government/uploads/system/uploads/ attachment_data/file/48317/4899-the-ccs-roadmap.pdf $>$.

3 Mainly power generation, but also other energy-intensive processes, such as steel and cement production. See examples of demonstration projects <www.globalccsinstitute.com/projects/browse>.

4 Saline aquifers seem to offer the greatest opportunities within Europe: it is estimated as sufficient for around 100 years' worth of Europe's emissions. A long-running pilot pre-combustion project (since 1996) has operated at the Sleipner natural gas processing facility in Norway, with around 1 million tonnes of $\mathrm{CO}_{2}$ extracted from natural gas and pumped into saline aquifers: see $<$ http://statoil.com/en/ $>$.

5 Cf J Goodell, How to Cool the Planet: Climate Engineering and the Audacious Quest to Fix the Earth's Climate (Houghton Mifflin Harcourt 2010). 
legal scrutiny has been slow to emerge, ${ }^{6}$ although in the wake of legislative efforts within Europe, we are now seeing a more focused attention to regulatory implications. ${ }^{7}$

The potential value of CCS is evident from reports that global emissions levels remain on a stubbornly upward trajectory, ${ }^{8}$ with rising demand for fossil fuels, ${ }^{9}$ especially for power generation. ${ }^{10}$ Global trends encapsulate a free rider problem that undermines any achievements that result in those jurisdictions that have in place emissions reductions policies supported by legal commitments. ${ }^{11}$ That said, experience in the UK suggests that claims for successful achievement of reductions require careful scrutiny. ${ }^{12}$ Further, of the UK power sector's proportion of 27 per cent of total UK emissions, ${ }^{13}$ around four-fifths of that figure remains reliant on fossil fuels. ${ }^{14}$ Meanwhile, globally, research carried out by the International Energy Agency (IEA) suggests that, with electricity-related $\mathrm{CO}_{2}$ emissions expected to double between 2007 and 2050, then to meet international objectives for a 50 per cent reduction in aggregate emissions to 2050, CCS would be required to contribute as much as one-fifth of that total reduction. ${ }^{15}$ CCS thus presents, if not quite a carbon version of the last chance saloon, then a potentially pivotal technological contribution toward climate change mitigation. ${ }^{16}$ Further, if it proves possible to establish CCS projects

6 Although much attention is evident in relation particularly to property law implications from US perspectives; this can be said to reflect such locational features as an abundance of sub-terrestrial sites with storage potential, alongside experience of smaller-scale technologies such as enhanced oil recovery, plus a high incidence of private rather than state ownership of underground rights: see A B Klass and E J Wilson, 'Climate Change, Sequestration, and Property Rights' [2010] University of Illinois Law Review 363; N R Hoffman, 'The Feasibility of Applying Strict-Liability Principles to Carbon Capture and Storage' (2010) 49 Washington Law Journal 527.

7 I Havercroft, R Macrory and R B Stewart (eds), Carbon Capture and Storage: Emerging Legal and Regulatory Issues (Hart Publishing 2011) offers an excellent introduction to key issues and comparative experiences to date; see also A Haan-Kamminga, M A Roggenkamp, E Woerdman, 'Legal Uncertainties of Climate Capture and Storage in the EU: The Netherlands as an Example' (2010) 4(3) Carbon and Climate Law Review 240; A Haan-Kamminga, 'Long Term Liability for Geological Carbon Storage in the European Union' (2011) 29(3) Journal of Energy and Natural Resources Law 309; G Kaminskaite Salters, Implementing the Carbon Capture and Storage Regime in the UK: The Challenges and Solutions' in M Peeters, M Stallworthy and J de Cendra de Larragan (eds), Climate Law in EU Member States: Towards National Legislation for Climate Protection (Edward Elgar Publishing 2012) ch 12.

8 For a survey of the scale of the problem and proposals for transforming energy sourcing and use, see T B Johansson et al (eds), Global Energy Assessment (International Institute for Applied Systems Analysis Report, CUP 2012).

9 Especially important where significant commitments to coal-fired generation persist: see eg Office of Management and Budget, A New Era of Responsibility: Renewing America's Promise (26 February 2009) $<$ www.gpoaccess.gov/usbudget/fy10/pdf/fy10-newera.pdf>.

10 In some states there is very high dependence on coal: eg over $90 \%$ in South Africa and Poland; near $80 \%$ in China, Australia: see <www.worldcoal.org/resources/coal-statistics>.

11 For instance, under the UK's Climate Change Act 2008.

12 According to the UK's Climate Change Committee, in 2011 (though the impact of low economic growth, rising fuel prices and a mild winter contributed to a substantial economy-wide fall in emissions) policy measures contributed only a circa $0.8 \%$ reduction, against an annual target of $3.0 \%$ : Fourth Annual Progress Report to Parliament (Climate Change Committee, July 2012) 51.

13 UK emissions statistics 2010 <www.decc.gov.uk/en/content/cms/statistics/climate_stats/gg_emissions/ uk_emissions/2010_final.aspx>.

14 Figures for 2010 were approximately as follows: gas (40\%), coal (32\%), nuclear (18\%), renewables $(7 \%)$, oil (3\%): www.decc.gov.uk/en/content/cms/statistics/energy_stats/source/electricity/electricity.aspx.

15 IEA (n 1) 1.1.

16 B Metz et al (eds), 'Summary for Policy Makers' in Special Report on Carbon Dioxide Capture and Storage (IPPC Working Group III, CUP 2005) 2-14. 
at large scale, then the current terms of debate over energy mix would be radically altered. ${ }^{17}$ This is partly on account of the abundance of coal (and to a lesser extent, gas) relative to other fuel sources. ${ }^{18}$ It also reflects circumstances in which (for the medium term at least), as compared with fossil fuels, most renewables remain significantly less competitive. ${ }^{19}$ Accordingly, a further challenge, aside from aspects of direct regulation, is to secure emissions cuts in spite of prevailing market conditions being favourable to continued exploitation of fossil fuels.

This article addresses key elements of the wider regulatory context into which CCS must be accommodated. The deepening reach of modern environmental regulation, marked by a gradual blurring of distinctions as between the private and the public, ${ }^{20}$ represents an aspect of what has been termed regulatory capitalism. ${ }^{21}$ An important side effect is that, whilst under pressure in an integrated policy arena, environmental law regimes remain relatively robust, arguably running counter to effects elsewhere from a hollowing out of the state, privatisation and regulation'. 22 This has been evident in those areas that involve high levels of uncertainty, now most vividly in the sphere of climate change. ${ }^{23}$ Risks inherent to CCS include not only significant costs exposures at its various stages of development, operation and regulatory compliance, but also a range of potential liabilities, both established and novel. The complex technologies involved and the potential exposure to liabilities, regulatory and otherwise, present major investment uncertainties. Whilst private investment and expertise appears essential for development and deployment, the state has vital economic and legal roles to play in assuring viability. Though most policy attention has focused on commercial risks in initial development, a state of uncertainty surrounds those contingent risks that attach to eventual storage, notwithstanding a harmonised framework established within the European Union (EU), ${ }^{24}$ now in course of

17 For instance, already demanding EU renewables targets may require revision in the event of successful technological developments, such as CCS (and in some jurisdictions further nuclear power investment): D Helm, 'EU Climate-Change Policy: A Critique' in D Helm and C Hepburn (eds), The Economics and Politics of Climate Change (OUP 2010) 237.

18 A feature of progress in extraction technologies is that figures do not remain constant, but at current rates of consumption, there may be over 120 years of available coal, though some estimates suggest several centuries' worth; cf though with a similar caveat, figures which suggest barely half-a-century for oil and in excess of 60 years or more for gas: see eg <www.worldenergy.org $>$. The latter figure in particular will require review in light of progress in the development of the technology known as 'hydraulic fracking', already extensive in the US: see R McKie, 'Fracking is Only Way to reach Obama's Goal on Climate Change, Says Top Scientist', Observer (London, 17 February 2013). The technology is expected to have a more limited relevance for the UK, although despite concerns at greenhouse damage from methane 'fugitive' emissions and risks of seismic tremor, the UK government has lifted a moratorium following review by the Royal Society/Royal Academy of Engineering: Shale Gas Extraction in the UK: A Review of Hydraulic Fracturing (RS/RAE, June 2012).

19 The burgeoning development of fracking in the US can also be expected to have collateral effects, including as lower-cost US coal penetrates world markets to a significant degree.

20 Cf E Fisher, 'Unpacking the Toolbox: Or Why the Public/Private Divide is Important in EC Environmental Law' in M Freedland and J-B Auby (eds), The Public and Private Law Divide (Hart Publishing 2006) 230-34.

21 See N Gunningham, 'Environmental Law, Regulation and Governance: Shifting Architectures' (2009) 21 JEL 179 , who suggests a resulting 'expansion rather than the retreat of regulation in new forms'.

22 Ibid 209

23 See R J Lazarus, 'Super Wicked Problems and Climate Change: Restraining the Present to Liberate the Future' (2009) 94 Cornell Law Review 1153 (2009).

24 Dir 2009/31/EC on the geological storage of carbon dioxide [2009] OJ L140/114; affording wide flexibility available to member states in setting financial security requirements for operators, through operational and post-closure (up until transfer of responsibility to the state) phases, to ensure that obligations under permit are met: arts 7(10), 19 (including as to liability arising from leakage in accordance with Dir 2003/87/EC establishing a scheme for greenhouse gas emission allowance trading within the Community [2003] OJ L275/32). 
transposition by those member states that regard CCS as both feasible and acceptable. ${ }^{25}$ There, it is notable that the state should perform the role of ultimate guarantor of longterm liability exposure. ${ }^{26}$ The approach contrasts with a more general reticence toward state underwriting of liabilities in cognate fields; seen, for instance, in the EU's environmental liability regime, ${ }^{27}$ and also domestically in governmental resistance to state underwriting of flood losses affecting newly at-risk areas (also linked to effects of climate change). ${ }^{28}$

Accordingly, as part of the regulatory task, finding an appropriate balancing as between state and private responsibilities will be crucial to securing effective implementation and regulation of CCS into the long term. The article proceeds as follows. Following an introductory review of underlying rationales, the argument will focus on three main themes. Whilst each is introduced separately, across a policy area that (in common with many new generation environmental challenges) fully justifies a polycentric labelling, there is considerable crossover between them. ${ }^{29}$ They address, first, the wider environmental governance context into which debates over CCS must take place; secondly, instrumental challenges raised by CCS in light of those public and market priorities that influence climate change and energy policy-making; and thirdly, key long-term risk regulation issues, especially concerning potential liabilities, that need to be addressed. Particularly in this latter respect, consideration of the appropriateness of command-and-control and economic regulatory mechanisms is offered, with specific consideration of longer-term risks (from leakage from storage sites) and drawing more general lessons from experience in other fields of environmental regulation.

\section{Rationale for CCS: its potential contribution to climate objectives}

Aspects of CCS technology are well known in discrete industrial applications, such as in enhanced oil recovery. ${ }^{30}$ These mostly operate on a small scale, yet to be applied in commercial power generation. ${ }^{31}$ Eventual deployment could take place by one of three identified capture methods. ${ }^{32}$ The first, a pre-combustion process (previously used in largescale chemical and fertiliser production) could be applied in power generation by producing hydrogen for use in gasification systems. ${ }^{33} \mathrm{~A}$ second process, operating post-combustion, follows relatively well-known technology, already in power generation by removal from flue

25 The UK's established regulatory framework will apply to all CCS-related activities, save the permitting of permanent storage: see Storage of Carbon Dioxide (Licensing etc) Regulations 2010/2221.

26 Ibid arts 18 (transfer of obligations from operator to state) and 20 (financial mechanism to cover a limited range of post-closure costs).

27 Dir 2004/35/EC on environmental liability with regard to the prevention and remedying of environmental damage [2004] OJ L143/56: see G Winter, J H Jans, R Macrory and L Kramer, 'Weighing up the EC Environmental Liability Directive' (2008) 20 JEL 163.

28 See J Morgan and M Stallworthy, 'Indemnifying against Flood Loss in a Changing Environment' [2013] 33 Legal Studies 239-63.

29 By contrast with typical point-source environmental risks, climate threats are causatively highly diffuse, with associated harms widely displaced both spatially and temporally: see H Bulkeley and P Newell, Governing Climate Change (Routledge 2010).

30 P M Marston and P A Moore, 'From EOR to CCS: The Evolving Legal and Regulatory Framework for Carbon Capture and Storage’ (2008) 29 Energy Law Journal 421.

31 For a breakdown of the current status internationally of around 78 large-scale integrated projects, see $<$ www.globalccsinstitute.com/resources/data $>$.

32 For succinct explanations, see N Shilling, 'Carbon Capture and Storage: An Equipment Manufacturer's Perspective' in Havercroft et al (n 7) 27-30; also K Thambimuthu et al, 'Capture of $\mathrm{CO}_{2}$ ', in Metz et al (n 16).

33 Fuel reacts with oxygen and air to produce a synthetic gas (syngas), mainly of hydrogen and carbon monoxide (CO), and the latter further reacts with steam to convert $\mathrm{CO}_{2}$ to be extracted (where coal is the fuel, termed an integrated gasification combined cycle). 
gases of pollutants such as sulphur (as well as in small-scale processes, such as soft-drinks carbonisation). ${ }^{34} \mathrm{~A}$ third alternative, oxy-fuel (or advanced) combustion, so far restricted to laboratory and small-scale pilots, would occur during combustion. ${ }^{35}$ If successfully demonstrated at large scale, each might be suitable for new installations. ${ }^{36}$ In contrast, for existing capacity, the pre-combustion method is not compatible with existing solid fuel combustion processes; ${ }^{37}$ although capture potential exists for post- or oxy-fuel combustion (respectively by retro-fit or re-powering of installations). ${ }^{38}$

The main justifications for CCS lie in support of (not always compatible) objectives for energy security and emissions reduction. All the above processes offer prospects for emissions reductions: the post- and pre-combustion methods with carbon capture rates of up to 90 per cent, and oxy-fuel combustion with an even greater potential for up to 98 per cent. The future role of fossil fuels could thereby be transformed, somewhat counter-intuitively contributing to low-carbon objectives, as part of the energy mix: with increased availability of 'acceptable' sources, within a more balanced energy portfolio. Further, the use of fossil fuels alongside CCS can ensure (unlike, for instance, wind power, which has the drawback of intermittency) a relatively constant reliability of supply (that is, baseload operation). Less quantifiably, CCS could, if effective, also obviate uncertain risks (and costs) from further diversion of effort into seeking alternative technological breakthroughs.

CCS is therefore heralded as part of a future low-carbon economy, objectives for which underpin the UK's legislative regime for limiting greenhouse emissions. ${ }^{39}$ Central government must meet mandatory statutory reductions, across periodic carbon budgetary periods. Policy initiatives in accord with this process have resulted in a commitment to rapid decarbonisation of power generation during the 2020s; and the statutory reporting body monitoring progress has set a 2030 objective for the sector of net carbon emissions close to nil. ${ }^{40}$ On current trends, however, this needs to be viewed against a total UK annual generation capacity requirement of over $80 \mathrm{GW}{ }^{41}$ Further, by the early 2020 s around a quarter of generation capacity will require replacing 42 in response to numerous factors: including closure requirements (by 2015) under the Large Combustion Plants Directive, ${ }^{43}$ stricter sulphur and nitrogen dioxide industrial emission limits, ${ }^{44}$ and anticipated end-of-life

34 Once the fuel has been burned, flue gas is cooled and reacts with a solvent allowing $\mathrm{CO}_{2}$ to be removed by means of a scrubbing process.

35 Nitrogen is removed from the flue gas when the fuel is burned in $95 \%$ pure oxygen, producing a flue gas of water vapour, which is then condensed, alongside $\mathrm{CO}_{2}$ which can then be separated off.

36 Currently, the most advanced demonstration (coal) plants each aim to divert $\mathrm{CO}_{2}$ for oil recovery (from 2014): Boundary Dam, Saskatchewan, Canada (post-combustion) and Kemper County, Mississippi, USA (precombustion): see eg 'North American Success', ENDS Report 445 (London, 22 February 2012) 28.

37 Reliant on burning pulverised coal.

38 Although in the latter case dependent on further technological advances and likely to incur appreciably higher costs.

39 See DECC (n 2) paras. 2.5-12; also, Climate Change Act 2008, pt I.

40 Cf no statutory commitment was included on the introduction of the Energy Bill (2012-13), save for a planned review of emissions objectives 2020-30 by 2016 (by reference to performance elsewhere in the EU).

41 DECC, Planning our Electric Future: A White Paper for Secure, Affordable and Low-Carbon Electricity (The Stationery Office 2011) 5-6.

42 DECC, Overarching National Policy Statement (NPS) for Energy (EN-1) (The Stationery Office, July 2011) pt 3.

43 Dir 2001/80/EC on the limitation of emission of certain pollutants into the air from large combustion plants [2001] OJ L 309/1 (27 November).

44 Dir 2010/75/EU on industrial emissions (integrated pollution prevention and control) (24 November). 
decommissioning of (all but one of) the current generation of nuclear power stations. ${ }^{45}$ The value of CCS to the task of capacity replacement can be envisaged from industry projections which suggest that (assuming proven technologically) around 20-30 GW could be CCS-linked by 2030.46 Government seems similarly ambitious, seeking a total of 40-70 GW of new low-carbon generating capacity over that same period, ${ }^{47}$ at least half of the median projection seemingly dependent on CCS deployment. Absent the unlikely achievement of reductions in net demand approaching an equivalent scale (for instance, through energy efficiency), ${ }^{48}$ CCS emerges as a significant factor in securing longer-term compatibility of energy and climate change measures.

\section{A governance perspective on regulating CCS}

The UN's Intergovernmental Panel on Climate Change (IPCC) has been at the forefront both of the broad consensus over anthropogenic causes of global warming 49 and concerning the potential mitigatory role of CCS. ${ }^{50}$ A growing cross-disciplinary engagement with climate change threats in the social sciences has also gained in political traction, ${ }^{51}$ with wide-ranging law and policy initiatives across numerous jurisdictions, ${ }^{52}$ although an ambivalent picture persists. ${ }^{53}$ Reliance on CCS may, in this light, prove a double-edged sword, if resulting in stasis, or 'business as usual', so deflecting attention away from other laws and policies that can otherwise 'facilitate processes, products, and patterns of behaviour which are good for the planet'. ${ }^{54}$ Within that wider picture, conflicting societal pressures have combined with a widespread inability among decision-makers consistently to prioritise low-carbon objectives, ${ }^{55}$ vividly exemplifying a new form of disconnect between social thought and social action. ${ }^{56}$ Legal responses to CCS can perhaps most advantageously be viewed from top-down perspectives, although it is interesting to consider first the relevance of a bottom-up approach to challenges posed.

The task of securing community buy-in, as part of the broader framework of climate change policy-making, raises participatory issues that are distinct from those seen more

45 See DECC, NPS for Nuclear Power Generation (EN-6) (The Stationery Office, July 2011) para 2.2; private sector resistance may likewise be leading to a new era of nuclear subsidy: D Carrington, 'Ministers Offer Nuclear Reactor Deal until 2050', Guardian (London, 19 February 2013).

46 CCS Association, A Strategy for CCS in the UK and Beyond (CCSA 2011).

47 DECC, Carbon Plan (2011) <www.decc.gov.uk/en/content/cms/tackling/carbon_plan/carbon_plan.aspx>.

48 Demand-side measures remain less of a government priority: see criticism by Energy and Climate Change Committee, Draft Energy Bill: Pre-legislative Scrutiny (First Report, HC 2012-13, 275-1, 23 July 2012).

49 IPCC, Climate Change 2007: The Physical Science Basis (Fourth Assessment Report, Working Group I, CUP 2007).

50 Metz et al (n 16).

51 For a critique of traditional economic perspectives on the processes for discounting future interests, see N Stern, Economic Impacts of Climate Change: The Stern Review (Cabinet Office/HM Treasury 2006).

52 See J de Cendra de Larragan, 'EU Climate and Energy Law: Challenges for Member States', in Peeters et al (n 7) $\mathrm{ch} 2$.

53 T Jackson, Prosperity without Growth: The Transition to a Sustainable Economy (Sustainable Development Commission 2009).

54 D R Boyd, 'Sustainability Law: (R)Evolutionary Directions for the Future of Environmental Law' [2004] Journal of Environmental Law and Practice 357, 365.

55 In light of the major uncertainties and costs that surround CCS, it has been argued that as a viable part of the 'carbon mitigation toolkit' it is substantially undermined by multisectoral deficits in what has been termed the 'issue-attention cycle': see S Shackley and B Evar, 'Up and Down with CCS: The Issue-Attention Cycle and the Political Dynamics of Decarbonisation' in N Markusson, S Shackley and B Evar (eds), The Social Dynamics of Carbon Capture and Storage: Understanding CCS Representations, Governance and Innovation (Earthscan/Routledge 2012).

56 C D Stone, 'Response to Commentators (Should Trees Have Standing?)' (2012) 3 Journal of Human Rights and the Environment 100, 114; also illustrating the condition of bounded rationality: see eg A Green, 'Self Control, Individual Choice, and Climate Change' (2008) 26 Virginia Environmental Law Journal 77. 
generally in environmental protection. For the UK, the emphasis on access to information and procedural issues, ${ }^{57}$ shown to most significant effect in land use planning, 58 may at first sight have only limited connection with CCS. For instance, local attributes that typically characterise community resistance are largely missing from a scheme based upon undersea storage. ${ }^{59}$ Yet two interrelated features point to the need to engage wider civil society in CCS: opportunities for participation can improve levels of engagement with environmental strategies more generally, ${ }^{60}$ whilst at the same time they can enhance the processes of legitimisation that can otherwise seem out of place in the face of scientific or technological complexity, ${ }^{61}$ a condition surely encompassing CCS. Evidence as to how this can be achieved can be seen in steps taken towards developing a Scottish government communication strategy, specifically for CCS. ${ }^{62}$ This works from the premise that efforts to secure public acceptance, through mediation and participatory mechanisms, are a precondition to effective application. ${ }^{63}$

Such efforts can be seen as supplementing wider discourse concerning reform of environmental governance, incorporating arguments for 'participatory dialogue and deliberation, devolved decision-making, flexibility . . . inclusiveness, transparency and institutionalised consensus-building'. ${ }^{64}$ Similarly, it has been argued (in a discussion of 'social shaping' of CCS in the Australian context) that the challenge for regulators is not only to structure regulatory regimes to facilitate more comprehensive engagement processes, but also to find a way to support proponents with a range of benefits, should they do this well'. ${ }^{65}$ There is also the wider European canvas on which participation commitments are mandated under the Aarhus Convention, ${ }^{66}$ applicable EU Directives ${ }^{67}$ and related national regimes (as in planning and strategic and project-based environmental assessment). ${ }^{68}$ Experience of these more general measures can inform debates over specific risk-based strategies to address benefits and costs of deploying CCS as a primary vehicle for securing emissions reductions. ${ }^{69}$

Turning to governance challenges more appropriately viewed from a top-down perspective, two illustrations are considered in the following discussion: first, the

57 W Howarth, 'Aspirations and Realities under the Water Framework Directive: Proceduralisation, Participation and Practicalities' (2009) 21 JEL 391.

58 S Owens and R Cowell, Land and Limits: Interpreting Sustainability in the Planning Process (Routledge 2002).

59 Cf B E Olsen, 'Wind Energy and Local Acceptance: How to Get Beyond the Nimby Effect' (2010) 19 European Energy and Environmental Law Review 239.

60 J Glicken, 'Getting Stakeholder Participation "Right": a Discussion of Participatory Processes and Possible Pitfalls’ (2000) 3 Environmental Science and Policy 305.

$61 \mathrm{~J}$ Steele, 'Participation and Deliberation in Environmental Decision-Making: Exploring a Problem-Solving Approach' (2001) 21 Oxford Journal of Legal Studies 415, 426.

62 J Hammond and S Shackley, Towards a Public Communication Engagement Strategy for Carbon Dioxide Capture and Storage Projects in Scotland (SCCS Working Paper 2010).

63 Ibid 13; cf the UK government's less particularized approach: DECC (n 2) 6.3.

64 Gunningham (n 21) 203.

65 P Ashworth and C Cormick, 'Enabling the Social Shaping of CCS Technology', in Havercroft et al (n 7) 259.

66 Aarhus Convention on Access to Information, Public Participation in Decision-making and Access to Justice in Environmental Matters (UN, 1998).

67 Especially Dir 2003/4/EC on public access to environmental information; Dir 2003/35/EC providing for public participation in respect of the drawing-up of certain plans and programmes relating to the environment.

68 For an analysis of the cross-applicability of existing UK measures to CCS, see M Lewis and N Westaway, 'Public Participation in UK CCS Planning and Consent Procedures', in Havercroft et al (n 7) ch 19; see also M Grecos, 'Carbon Capture and Storage: An Environmental Assessment' [2010] JPL 8, 12-15.

69 For a US perspective, see eg Shilling (n 32) 31. 
implications of the limited degree of international law engagement in CCS; and, secondly, the burgeoning field of UK and EU climate change law and policy activity, highlighting the impact of CCS expectations upon wider concerns for energy sourcing. From the perspective of international law, Bugge has pointed out that legal issues of transboundary $\mathrm{CO}_{2}$ chains under CCS are undertheorised. ${ }^{70}$ Furthermore, the multilateral climate regime established under the Framework Convention on Climate Change ${ }^{71}$ and original arrangements under the Kyoto Protocol, which (to 2012) placed selective obligations on states for emissions reductions, provide no formal rules specifically referable to CCS. ${ }^{72}$ There has been no substantial impetus towards securing formal international agreement over CCS, in contrast with other areas of transnational risk. This perhaps reflects a shared, relatively sanguine approach to environmental risk in the CCS context, in notable contrast with the concern, say, for transboundary harms from nuclear accidents, referred to below. Nevertheless specific threats from, say, leakage from CCS storage sites add to an already fragmented picture of international law, ${ }^{73}$ just as climate change impacts more generally threaten underlying objectives of a range of multilateral environmental agreements, ${ }^{74}$ such as the Convention on Biological Diversity. ${ }^{75}$

Indeed, attempts at producing geo-engineering solutions to climate threats raise novel issues of international law, ${ }^{76}$ not least because there has hitherto been limited experience of a need 'to address large-scale human efforts to alter the environment'. ${ }^{77}$ Short of any framework measure, CCS will fall to be taken into account on a case-by-case basis under discrete international regimes. The most significant example of this effect to date relates to controls placed upon dumping of waste materials. A prohibition of offshore sequestration under CCS, which had been contained in the 1996 London Protocol $^{78}$ to the 1972 Convention on the Prevention of Marine Pollution by Dumping of Wastes and Other Matter, ${ }^{79}$ was lifted in 2007, subject to conditions based upon risk assessment and a management framework. ${ }^{80}$ The effect is limited to permitting storage of captured $\mathrm{CO}_{2}$ under the seabed and there remain therefore general concerns for international

70 For a discussion of uncertainties regarding allocation of state responsibilities across capture, transport and storage cycles, see H C Brugge, "Transboundary Chains for Carbon Capture and Storage: Allocation under the Climate Regime between the States Parties of Emissions Due to Leakage' in Havercroft et al (n 7).

7131 ILM (1992) 851.

72 Though it was confirmed at the conference of parties, Cancun (2010), that CCS may qualify in principle as a project activity under Kyoto's Clean Development Mechanism: Decision 7/CMP6 $<$ www.unfcc/int.documentationo.decisions/items>; see further Brugge (n 70).

73 H Van Asselt, F Sindico and M A Mehling, 'Global Climate Change and the Fragmentation of International Law' (2008) 30 Law and Policy 423.

74 See C Redgwell, 'Climate Change and International Environmental Law' in R Rayfuse and S V Scott (eds), International Law in the Era of Climate Change (Edward Elgar Publishing 2012).

751670 UNTS 79.

76 See C Redgwell, 'Geoengineering the Climate: Technological Solutions to Mitigation Failure or Continuing Carbon Addiction?’ (2011) 2 Carbon and Climate Law Review 178.

77 Redgwell (n 74) 138-40, referring exceptionally to the Convention on the Prohibition of Military or Any Other Hostile Use of Environmental Modification Techniques, which suggests in some respects a model which might be modified for civil application.

7836 ELM 1 (in force March 2006).

7911 ILM 1294.

80 See R G Lee, 'Sub-seabed Carbon Sequestration: Building the Legal Platform' (2009) 30 Liverpool Law Review 131; also, C Redgwell, 'International Legal Responses to the Challenges of a Lower Carbon Future: Energy Law for the Twenty-First Century' in S Farrell, T Ahmed and D French, Criminological and Legal Consequences of Climate Change (Hart Publishing 2012) 42-45. 
responsibility and liability for leakage and other damage to the marine environment', ${ }^{81}$ which can be linked, as seen above, with the lack of movement toward international agreement. ${ }^{82}$

The second illustration, which raises issues as to energy choices at national (and regional) levels, relates to the sourcing of energy and the danger of unsustainable 'lockin'. ${ }^{83}$ The lack of experience of large-scale CCS presents the energy sector with a temporal quandary. A consensus view suggests that the earliest that deployment might be expected to begin would be around $2030 .{ }^{84}$ The installation of CCS infrastructure and systems to anything approaching sufficient scale might not then realistically be expected until around mid-century. 85 This poses a more fundamental problem in light of the close links between future expectations for CCS and levels of fossil fuel use in the meantime, the timescale standing in the way of a shift away from non-sustainable energy sources. ${ }^{86}$ The effect might prove temporary, as an essential means of securing the transition to a low-carbon future, with CCS seen as an essential 'bridging technology' towards climate change mitigation. ${ }^{87} \mathrm{On}$ the other hand, if the effect were to reinforce the impact of system inertia under settled institutional arrangements (public and private), ${ }^{88}$ the biosphere may be brought closer to what climate scientists term a tipping-point. ${ }^{89}$

Major consequences follow: first, in the coming decades, and before significant levels of CCS can be put in place, the extension globally in fossil fuel-generating capacity will be less likely to abate, ${ }^{90}$ with linked infrastructure investment expected to have a lifespan in excess of 40 years. To counter this, some regional regimes, applying the more direct coercive approaches of command-and-control, may insist upon 'carbon capture ready' installations. Under EU legislation, whilst CCS deployment is not mandatory, ${ }^{91}$ member states are now required to assess new projects for this purpose, ${ }^{92}$ and (where capture is feasible) to provide suitable site capacity for that future event. Thus, subject to overall emission limits set under

81 R Rayfuse, 'Climate Change and the Law of the Sea' in Rayfuse and Scott (n 74) 166-69.

82 Informally, a Clean Energy Ministerial of participating states shares lessons and best practice through a Carbon Capture Use and Storage Action Group: <http://cleranenergyministerial.org/ events/cem3/index.html>.

83 P J Vergragt, N Markusson and H Karlsson, 'Carbon Capture and Storage, Bioenergy with Carbon Capture and Storage, and the Escape from the Fossil-Fuel Lock-in' (2011) 21 Global Environmental Change 282.

84 See, for instance, UN Development Programme, Avoiding Dangerous Climate Change: Strategies for Mitigation (Human Development Report, UN 2007/08) 145-46.

85 E Rubin, 'Technical Summary', in Metz et al (n 16) 41. The IEA suggests that respectively 100 and 3000 largescale plants are required to be in operation by 2020 and 2050.

86 G C Unruh, 'Understanding Carbon Lock-in' (2000) 28 Energy Policy 817.

87 Dir 2009/31/EC (n 24) preamble, para 4; see S Shackley and M Thompson, Lost in the Mix: Will the Technologies of Carbon Dioxide Carbon Capture and Storage Provide Us with a Breathing Space as We Strive to Make the Transition from Fossil Fuels to Renewables?' (2012) 110 Climatic Change 101

88 Both privatized, free market and public, regulatory approaches are capable of imposing externalities, in effect applying discount rates upon the protection of future environmental interests: see D H Cole, 'Clearing the Air: Four Propositions about Property Rights and Environmental Protection’ (1999) 10 Duke Environmental Law and Policy Forum 103, 117-25.

89 See J Hansen, 'A Slippery Slope: How Much Global Warming Constitutes "Dangerous Anthropogenic Interference"?’ (2005) 68 Climatic Change 269.

90 See eg Johansson et al (n 8).

91 Dir 2009/31/EC (n 24) art 4; this reflects such factors as continuing uncertainty as to when the technology will be available for successful deployment, disparities in geological features, as well as in evidence of public concern.

92 Applicable to proposals for new 300MW-plus combustion plants, requiring assessment as to the availability of storage sites and feasibility of transport facilities: ibid art 33. 
the Emissions Trading Directive (EU emissions trading scheme (ETS)), ${ }^{93}$ such installations can continue to be built and permitted for electricity generation, lack of CCS notwithstanding. This might be ameliorated if EU-wide energy performance standards were imposed, effectively ruling out certain forms of generation until CCS becomes available. ${ }^{94}$ In the UK's case, its 2012-13 Energy Bill contains proposals for an energy performance standard, which, absent CCS, would effectively rule out further substantial investment in coal-fired power stations. ${ }^{95}$

Secondly, the expectation of CCS offers incentives to decision-makers to scale down commitments to low-carbon investment. ${ }^{96}$ The significance of this is comparable with that arising from so-called carbon leakage, produced by outsourcing of industrial production (and thus carbon emissions) to developing economies. ${ }^{97}$ This has led to calls for 'border tariffs' on carbon intensive imports, so as to shift focus onto 'consumption of embodied carbon dioxide emissions, rather than production'. ${ }^{98}$ But an important consequence of the above is that private investment decisions, faced with the resulting uncertainties, will respond accordingly, a logic which still applies with considerable force in the energy markets. ${ }^{99}$ So long as market-makers are confident of sourcing fossil fuels at competitive prices, then in default of further regulatory constraints this can justify further diversion of resources away from alternatives.

\section{CCS and re-regulating the energy system}

The task of addressing those financial risks that determine investment decisions is thus a key factor in framing regulatory terms for CCS. Investment obstacles arise across a range of timeframes, but an early test relates to securing seed-corn funding in advance of capacity to make informed judgments affecting CCS for the future. Significant cost exposures accrue through project lifecycles. These arguably place CCS beyond the commercial capabilities of both the industries directly concerned (in view of the costs of financing such ventures and the shorter-term returns expected by shareholders) and those capital markets that support investment (for instance, through equity or loan stock issues, or other forms of leveraged finance). For early-movers, the vexed question of start-up costs exemplifies a form of 'chicken and egg syndrome', on account of the lack from the outset of the kind of reliable performance data that is normally a prerequisite to investment decisions. ${ }^{100}$ In these

93 Dir 2003/87/EC (n 24); Decision No 406/2009/EC on the effort of member states to reduce their greenhouse gas emissions to meet the Community's greenhouse gas emission reduction commitments up to 2020 [2009] OJ L140/136.

94 Following review of CCS readiness that the European Commission is required to carry out (in 2015): see Dir 2009/31/EC (n 24) art 38.

95 Under cl 38, maximum annual emissions from all new plant (over 50MW) would be limited to $450 \mathrm{~g}$ $\mathrm{CO}_{2} / \mathrm{KWh}$; rather than (ironically) 'undermining decarbonisation', CCS plants were subject to the same restriction after the draft Bill stage: Government Response to HC Energy and Climate Change Committee Report on the Draft Energy Bill (Cm 8504 November 2012) 30-21.

96 Greenpeace International, False Hope: Why Carbon Capture and Storage Won't Save the Climate (Greenpeace 2008) pt 4.

97 W Straw, D Nash and R Balfour, Europe's Next Economy: The Benefits of and Barriers to Low-Carbon Transition (Institute for Public Policy Research, May 2012).

98 See C Hepburn, 'The Energy Mix, Carbon Pricing and Border Carbon Adjustments' (2012) 24 Environmental Law and Management 177, 181; also, D Helm, C Hepburn and G Ruta, 'Trade, Climate Change and The Political Game Theory of Border Carbon Adjustments’ (2012) 28 Oxford Review of Economic Policy 368.

99 See D Helm, 'Climate Change Policy: Why Has So Little Been Achieved?' (2008) 24 Oxford Review of Economic Policy 211.

100 J P Tomain, Ending Dirty Energy Policy: Prelude to Climate Change (CUP 2012) 113. 
circumstances the logic of the market would suggest that investment can be more advantageously directed elsewhere.

In view of the potential benefits from CCS, threats to commercial viability have significant implications for the public sphere, ${ }^{101}$ and hence the broad acknowledgment of the need for public investment and state support towards costs especially of early demonstration projects. Yet, in the UK the government's 'commercialisation programme' has met considerable private sector resistance, reflecting (as well as restrictive terms on offer) an industry belief that proposals fall short of what is needed. ${ }^{102}$ Likewise, though for different reasons, EU supplementary support for CCS has also been called into question. Its funding, reliant on allocations from the EU ETS 'new entrants reserve', 103 has been beset by delay, and is handicapped by depressed ETS carbon allowance prices, eroding subsidy levels. ${ }^{104}$ Nevertheless the link between CCS and the ETS for funding purposes creates a valuable precedent. Early phases of ETS supported grandfathering through free distribution of allowances. From 2013 auctioning is being introduced for some sectors, so the capability arguably exists (despite fears of carbon leakage as costs increase) for generating a funding base which might be specifically earmarked for future CCS and other low-carbon initiatives.

Looking toward operational phases, both economic and environmental costs can be expected to be significant. These include threats to sustainability from a growing need to 'allocate more and more energy just to obtain energy', and thus 'declines in energy returned in energy invested'. ${ }^{105}$ For instance, it has been estimated that retro-fitting CCS capacity to existing plants could result in a 50 per cent increase in capital costs. ${ }^{106}$ So-called 'energy penalties' are also of potential significance, representing efficiency losses through the extra energy consumption that CCS requires. ${ }^{107}$ Further overall costs to the generator are variously assessed, from around a 20 per cent increase to a near doubling, ${ }^{108}$ at the higher end, especially on expensive coal-firing retro-fit. ${ }^{109}$ Moreover, though much the most significant, such costs largely relate to capture alone, whereas investors must take account of further costs at remaining CCS stages (infrastructure itself, transport to storage sites, maintenance and monitoring thereafter). Thus (especially with large-scale CCS not yet

101 W B Jacobs, L Cohen, L Kostakidis-Lianos and S Rundell, Proposed Roadmap for Overcoming Legal and Financial Obstacles to CCS (Discussion Paper 2009-04, John F Kennedy School of Government, Harvard 2009) 18-22, proposing an 'equitable approach' based on public-private cost-sharing: with federal support by capping liabilities for 'earliest movers' (demonstration projects); and subsequently for all sequestration site operators, in excess of any funds contributed by the industry ex ante (financial assurance or risk pooling).

102 With $£ 1$ billion demonstration project subsidy through competitive process; subsequently relaunched on new terms: see ENDS Report 447 (London, April 2012) 34-35; ENDS Report 448 (London, May 2012) 12.

103 The 'NER 300' project is based on 300 million allowances available (until 31 December 2015), for up to 10-12 demonstration projects (with a maximum for any one of 45 million allowances).

104 'CCS at Risk Following Carbon Price Collapse', ENDS Report (London, 16 November 2011); also, 'CCS and Renewables Plans Hit by EU Finance Blow', ENDS Report (London, 12 July 2012); 'Cash for Carbon Capture Projects Slashed by Eurozone Crisis', Guardian (London, 6 August 2012).

105 See J P Manno, 'Less Energy, Better Health' in L Westra, L Soskolme and D W Spady, Human Health and Ecological Integrity: Etbics, Law and Human Rights (Earthscan/Routledge 2012) 83-86 (analogy with the action of entropy under Second Law of Thermodynamics seems clear).

106 McKinsey \& Co, Carbon Capture and Storage: Assessing the Economics (Report, McKinsey \& Co 2008) 10

107 Estimates are for between $10 \%$ and $40 \%$ of electricity produced being lost in this way: see Metz et al (n 16) 3 .

108 Rubin (n 85) 40-43.

109 Massachusetts Institute of Technology, The Future of Coal (MIT 2007) 29 <http://web.mit.edu/coal/ The_Future_of_Coal.pdf $>$. 
proven) doubts over prospects for cost-competitiveness remain key determinants in energy market responses. ${ }^{110}$

It is therefore relevant to explore aspects of the wider relationship between the state and energy markets. There has long subsisted a curious disconnect between energy and the environment in policy-making and legal frameworks. ${ }^{111}$ Indeed, traditionally, discrete approaches and priorities have tended to defy the capacity for environmental law in other contexts to integrate into other fields. ${ }^{112}$ As recently as 1995, echoing a prevailing deregulatory agenda since the 1980s that has affected the energy markets as elsewhere, 113 the UK government was persisting in seeing 'no reasons why the electricity market should not of its own accord provide an appropriate level of diversity'. ${ }^{114}$ Yet obstacles in the way of maximising low-carbon energy investment require an energy policy framework, especially where there is a perceived need for incentives. ${ }^{115}$ Dual objectives for climate change mitigation and energy security have become a catalyst for a departure from the hands-off approach, with current legislative proposals being described as pointing towards a form of 're-regulation of the energy system'.116 Similarly, albeit that the EU enjoys more limited competences in respect to energy as compared with the environment, the European Commission has acknowledged the need for more effective policy responses, for 'energy and the environment can no longer be viewed in isolation'. 117 Thus efforts towards meeting objectives of security, diversity and sustainability are creating a renewed focus on directed energy planning, albeit superimposed onto the liberalised market structure, ${ }^{118}$ of which the Energy Bill is a complex manifestation.

New forms of selective state interference in energy markets can be illustrated, first, in legislative proposals for 'electricity market reform'.119 These include an overhauling of public incentives for low-carbon investment, replacing a mechanism based on a somewhat hit-or-miss feed-in tariffs (FiT) procedure, ${ }^{120}$ by offering fixed, differential payment guarantees (for up to 25 years), ${ }^{121}$ also available for utilisation of CCS. The idea in principle

110 DECC (n 2) 4.2 .

111 Not a UK phenomenon alone: see, for instance, L D Davies, 'Alternative Energy and the Energy-Environment Disconnect' (2010) 46 Idaho Law Review 473.

112 Cf N Dhondt, Integration of Environmental Protection into Other EC Policies (Europa Law Publishing 2003).

113 One incident arguably being a former moratorium on new nuclear investment (expensive both in set-up costs, long-term risks and potential liabilities), more recently superseded by proposals for a new generation of nuclear power stations; in the meantime regulators have approved extended terms in the useful lives of some installations still in operation: see DECC (n 45).

114 Department of Trade and Industry (DTI), The Prospects for Nuclear Power in the UK: Conclusions of the Government's Nuclear Review (Cm 2860, 1995) 2.7-8; at that time concluding that no near-term justification existed for a new generation of nuclear power stations.

115 See, for instance, M Pallemaerts, 'Climate Change, Natural Gas and the Rebirth of Energy Policy' in P Winand (ed), Securing Sustainable Energy Supplies in Europe and Australia (Pieter Lang 2011).

116 Energy and Climate Change Select Committee, Draft Energy Bill: Pre-legislative Scrutiny (First Report, HC 2012-13 275-1 July 2012) ch 9.

117 European Commission, An Energy Policy for the European Union (White Paper COM(95) 682 final, 13 December 1995) para 128.

118 A significant milestone for the new era of energy planning was the DTI, Conclusions of the Review of Energy Sources from Power Generation (HMSO 1998).

119 Energy Bill 2012-13, pt 1.

120 Under Energy Act 2008, ss 41-43, which arguably led to an undue advantage for solar voltaic installations; an attempt by the minister to reduce subsidy levels with partly retrospective effect was struck down in $\mathrm{R}$ (Homesun Holdings Ltd) $v$ Secretary of State for Energy and Climate Change [2011] EWHC 3575.

121 Under a Renewables Obligation, electricity suppliers have been required to purchase (increasing proportions of) generated power from renewable sources, and low-carbon generators receive market prices topped up by guaranteed payments under tradable Renewables Obligation Certificates. 
secures two advantages: greater certainty for investors, 122 under long-term 'contracts for difference' (FiT CfD), ${ }^{123}$ alongside greater protection for the taxpayer. ${ }^{124}$ Low-carbon investment would thereby be cushioned from carbon price collapses (so protecting market competitiveness against fossil fuel generation) whilst potential windfalls from higher carbon prices could be subject to claw-back. Secondly, as previously seen, an emissions performance standard is proposed, ${ }^{125}$ effectively ruling out non-CCS abated coal-fired stations; ${ }^{126}$ co-existing with a separate requirement that all new fossil fuel (in effect, gasfired) power stations be 'carbon capture ready'.127 A third, related mechanism, focuses on pricing, seeking a more consistent incentivising of low-carbon technology through the introduction of a national carbon price floor (from April 2013). ${ }^{128}$ This would limit the impact of depressed price levels for the allowances that must be purchased by installations that exceed allotted caps under the EU ETS scheme. ${ }^{129}$

Interventions such as through FiT CfD depend on a level of support that produces 'greater revenue certainty ... . [which] should lead to developers being able to reduce the costs of financing their investments'. 130 The specific inclusion of CCS is aimed at facilitating its development 'into a mature technology capable of being assessed by investors on a normal commercial basis'. ${ }^{131}$ Although the consequence would be to secure reduced carbon intensity of the energy system alongside increased energy security, the operation of the markets will continue to exert a major influence on outcomes. An emerging feature, for instance, with coal in the UK and much of the rest of the EU having been in decline (perhaps to be invigorated depending on events affecting CCS), has seen prospects for gas on a strongly upward curve. Despite extensive price increases in recent times, this arguably reflects continuing industry concerns at levels of low-carbon investment, as well as increased confidence in levels of global gas supply. ${ }^{132}$ Here fundamental tensions are apparent as to the implications of a new 'dash-for-gas', increasing:

122 DECC (n 47) 3.53, following the Climate Change Committee's recommendations for the fourth carbon budget (up to 2027), in accord with the obligations under Climate Change Act 2008, ss 12, 14.

123 Energy Bill 2012-13, cls 2-16.

124 It is the intention that FiT CfD replaces the Renewables Obligation, the former financial support mechanism incentivising renewable energy projects, by 2017.

125 Absent EU action likewise, European Commission approval would be required to allay the risk of legal challenge: see L Squintani, M Holwerda and K de Graaf, 'Regulating Greenhouse Gas Emissions from EU ETS Installations: What Room is Left for Member States?' in Peeters et al (n 7).

126 Energy Bill 2012-13, cl 38(1)(2); though not ruling out gas (also a fossil fuel, but around 60\% more carbon efficient).

127 The Bill enables ministerial regulations with the effect of disregarding emissions from such plants using CCS technology for the purpose of meeting emissions limits: cl 38(6)(a), (7)(a)(b)(c).

128 Although market circumstances differ, the minimum guideline price appears not to be significantly out of line with the conclusions of a 2007 report by MIT, which suggested that the carbon price should not fall below $\$ 25$ per tonne: see J Deutch and E J Moniz, The Future of Coal: An Interdisciplinary Study $<$ http://web.mit.edu/coal/>.

129 Attempts to impose EU-wide measures to support ETS market prices have so far been unsuccessful: see D Carrington, 'Blow to Green Hopes after Price of Carbon Permits Fall to Record Low', Guardian (London, 25 January 2013). The UK's national scheme would be introduced by adjustments in its domestic climate change levy.

130 DECC (n 2) 4.6.

131 Ibid 4.3.

132 IEA, World Energy Outlook. 2012 <www.iea.org/publications/freepublications/publication/English.pdf>. 
the risk of locking the UK into a high-carbon electricity system and represents a huge gamble on the eventual availability of cost effective [CCS] technology for gas plants. This could pose a severe threat to the achievement of our long term climate change goals. ${ }^{133}$

There are therefore considerable obstacles in the way of intervention efforts to nudge the energy economy onto a different trajectory by assisting low-carbon generators better to absorb price risks, ${ }^{134}$ without disabling the confidence of those whose energy choices remain largely constrained by the market. ${ }^{135}$ Outside of the advantages of a free market, its raison d'etre does not lie in the delivery of regulatory goals. Indeed, there is a propensity if unchecked to externalise costs, especially in the face of unknowable risk; a characteristic of problems posed by climate change generally, and in some respects also by CCS. Such consequences for low-carbon energy can be witnessed as above in market signals that favour renewed reliance on gas, and there remains a risk that these electricity market reforms will perpetuate a 'stop-start approach' to low-carbon investment. ${ }^{136}$

With effective regulatory frameworks crucial determinants towards successful deployment of CCS, ${ }^{137}$ experience of early development projects will afford opportunities to test aspects of suitability. ${ }^{138}$ Regulatory responses must address inherent risks from failures across the whole capture-transportation-storage cycle, alongside new dilemmas from uncertainties attaching to potential liabilities. Before exploring further, some comment is necessary regarding the wider EU legal context, where, as in the UK, we are witnessing a growing interdependence across fields of energy and climate change. New legislative incursions are in the course of development, following the catalysing effect of the 2007 Lisbon Treaty, which introduced an autonomous energy title, ${ }^{139}$ contrasting with a previous legal model which failed to address energy on its own account. ${ }^{140}$ Whilst EU constraints are increasingly influential, ${ }^{141}$ widespread national autonomy persists as to the detail of climate change policy; and similarly energy policy is still largely determined at member state level, ${ }^{142}$ with, for

133 Energy and Climate Change Select Committee, UK Energy Supply: Security or Independence? (Eighth Report 2010-12, HC 1065, October 2011), para 103.

134 In August 2012 DECC issued a call for evidence on barriers to securing long-term power purchase agreements.

135 Delays in provision of EU and UK financial support (already affecting the competitive process for demonstration projects and possibly also uncertainties as to longer-term guarantees or assumptions of liability) have produced so called 'investor fatigue' as proposals have been withdrawn and major hydrocarbon companies vacated the market: see DECC Science Advisory Group, Briefing Note on Carbon Capture and Storage (DECC, July 2011) 10-11.

136 See ENDS Report 452 (London, September 2012) 5-6.

137 Sites in principle in the UK are all offshore and include depleted hydrocarbon reservoirs, active fields with opportunities for enhanced hydrocarbon recovery, and deep saline aquifers: see DECC (n 2) 40, for a study of UK storage capacity, which is estimated to be enough for 100 years of current use, representing less than a quarter of potential storage capacity.

138 Following a mock CCS project the Scottish government and Scottish Centre for Carbon Storage have already produced a regulatory test toolkit, commended by the European Commission as a model of best practice: <www.scotland.gov.uk/Topics/Business-Industry/Energy/resources/Publications/CCSREgulatoryToolkit>.

139 Art 194 TFEU; expressed to be without prejudice to law-making powers under the Treaty's environmental title (art 191).

140 Early fruit of which shift can be seen in Dir 2012/27/EU on energy efficiency [2012] OJ L315/1 (14 November).

141 Eg EU ETS Dir 2003/87/EC (n 24); also Effort-Sharing Decision No 406/2009/EC (n 93).

142 See further Pallemaerts (n 115). 
instance, the energy title explicitly reserving national sourcing of energy supply. ${ }^{143}$ The EU is further limited in its choice of instruments, a prime illustration of which has been its inability to make any headway in extending its competence in relation to green fiscal measures. ${ }^{144}$

\section{Future regulatory challenges for CCS}

The choice and terms of suitable CCS regulatory mechanisms appear analogous to those used by the EU elsewhere in response to climate change. ${ }^{145}$ This broadly relies on utilising command-and-control methods alongside market-based alternatives, as exemplified by efforts through the EU ETS to encourage CCS by express inclusion in its scope. Here we see a paradigm illustration of markets in non-directed economies as both the prime vehicle for resource exploitation, as well as the basis for a shift toward economic mechanisms which nevertheless create further complex problems of regulation. ${ }^{146}$ In principle, captured carbon volumes under CCS are not classified as emissions, but compliance with mandated mitigation commitments being at stake, any subsequent leakages would be transformed into non-permitted emissions by a process of accounting adjustment. ${ }^{147} \mathrm{~A}$ cost would then be imposed by the triggering of a requirement to surrender emissions allowances equivalent to the estimated extent of leakage. Such a deterrence strategy, however, is vulnerable to low carbon prices, ${ }^{148}$ and a continuing failure under ETS to assure realistic pricing (to shift the balance of investment advantage away from non-mitigated fossil fuels emissions) constitutes a significant constraint on development of CCS. ${ }^{149}$

For the most part, however, the EU's CCS framework can be described as premised upon command-and-control, primarily founded on a permitting regime. ${ }^{150}$ The new regulatory focus is upon the feature of storage, including site selection, risk management and closure. A pervasive uncertainty relates to risks of harm from migration from storage sites: including, as seen above, to climate change mitigation goals, but also harm to human health or property and to the wider environment. Risks can arise in ways that are novel in their application to CCS, especially related to long-term storage, with potentially openended liabilities. They can also arise in ways that are incidental to existing public law regimes, or under established private law causes of action. In the latter respect, relevant harms are likely to be more localised, and for UK purposes would include common law rules for establishing liability for harm to persons and property. From a health perspective, for instance, $\mathrm{CO}_{2}$, whilst unlike oxygen not explosive or otherwise flammable, is corrosive, and leakage in confined spaces carries a threat of asphyxiation even at concentration levels of

143 The 2012 disaster at Fukushima has led to contrasting national responses: the UK remains formally committed to a new generation of nuclear power stations, whereas Germany, for instance, is now committed to phase them out.

144 A Jordan, et al, 'Governing with Multiple Policy Instruments?' in A Jordan and C Adelle (eds), Environmental Policy in the EU (3rd edn, Earthscan/Routledge 2013).

145 For a useful summary of measures differentiated by regulatory category, see ibid 317 .

146 R Macrory, 'Regulating in a Risky Environment' [2001] Current Legal Problems 619.

147 See Dir 2009/31/EC (n 24) art 16.

148 A discouraging general trend persists: see n 104, charting a recent fall to $€ 2.38$ per tonne, far below levels required for stimulating investment (circa €20-plus). Moreover political obstacles have thus far stymied Commission attempts to bolster prices through a temporary withholding of allowances from the market: see F Harvey and A Vaughan, 'MEPS Reject Key Reform of Emissions Trading Scheme', Guardian (London, 16 April 2013).

149 Committee on Climate Change, Meeting Carbon Budgets (Third Progress Report to Parliament, Stationery Office, June 2011) 17-18.

150 Dir 2009/31/EC, arts 6-16 (including the permit regime, alongside monitoring, reporting and remedial measures); an exploration permit is required under art 5. 
as low as 3 per cent by volume. ${ }^{151}$ However, for the UK (with only offshore storage currently envisaged), health risks are more likely to result from operational activities, including transportation, and are less likely to follow from migration from storage.

In relation to public law impacts, certain discrete environmental protection regimes have a potential for overlap with CCS regulation. In numerous instances, compliance with established regulatory arrangements protecting against pollution or harm to the wider environment will be required, ${ }^{152}$ including those relating to air pollution, soil contamination, surface or ground water pollution, ${ }^{153}$ and damage to habitats. A significant area of cross-cutting regulation affects risks of harm to the wider environment and the mandatory requirements for corrective measures under the Environmental Liability Directive. This directive recognised extended notions of harm, each of which might be relevant to CCS: including land or soil contamination with serious risk to public health; water pollution involving reduced ecological or chemical quality status; or other environmental harms in the event of significant damage caused by defined dangerous activities that pose risk to humans and the environment (as regulated elsewhere under EU legislation and thus within EU legal competence). ${ }^{154}$

By contrast, with CCS storage being of its nature intended to be permanent and not temporary, ${ }^{155}$ the application of certain other regimes can be inappropriate. These include those conditional protections and exemptions for purposes of marine protection under specific arrangements for licensing of deposit of articles or materials on the sea bed in relation to construction activities. ${ }^{156}$ Other domestic and EU regimes could in principle be in conflict with activities sanctioned by CCS permitting. These mainly relate to waste control and measures against dumping at sea (also, obligations under international law referred to previously), and it has been necessary to negotiate the terms on which exemptions might apply. Thus capture, transport and storage are expressly excluded from the definition of waste under the Waste Framework Directive. ${ }^{157}$ By contrast, capture facilities are subject to public regulation in the same way as the parent-generating installations of which they form part, ${ }^{158}$ and likewise transport of compressed $\mathrm{CO}_{2}$ by pipeline is subject to legislation already in place for the oil and gas industry. 159

Apart from such differential regulatory applications, a distinctive feature of CCS relates to post-closure risks arising during the storage phase (that is, post-capture, transport and

151 It is denser than air and will pool in low-lying areas, posing hazards to those exposed where ventilation is poor: see further D Spreng et al, 'CO 2 Capture and Storage: Another Faustian Bargain?’ (2007) 35 Energy Policy 850.

$152 \mathrm{Eg}$ art 31, amending Dir 85/337/EEC concerning environmental impact assessment of projects (such as capture, transport and storage).

153 Ocean acidification is a major reason why underwater dispersal is not seriously considered for CCS purposes, though carbon leakage from sites may yet pose future threats.

154 Strict liability applies. The directive further recognises specifically environmental claims for biodiversity damage (in the very specific sense of serious prejudice to the conservation status of EU habitats and wild birds directives), on the basis of a fault-based liability on account of any activities (whether or not otherwise regulated). The directive is constrained in numerous further respects: neither operating retroactively, nor extending to harm to personal interests in property or economic loss, any remedy for which remains a matter for national civil liability arrangements. It is moreover open to member states to apply state-of-the-art and regulatory compliance defences.

155 See also Water Resources Act 1991, s 88.

156 Food and Environmental Protection Act 1985, pt II.

157 Dir 2009/31/EC (n 24) art 35, amending Dir 2006/12/EC, art 2(1)(a); also art 36, excluding the shipment of waste under reg 1013/2006, art 1(3).

158 Electricity Act 1989, s 36.

159 Such as authority for onshore pipeline construction under the Pipelines Act 1962; see also Pipeline Works (Environmental Impact Assessment) Regulations 2000/1928. 
injection). ${ }^{160}$ With an indefinite potential for causing subsequent environmental and other harms, further questions of risk acceptability and commercial viability arise. In most jurisdictions addressing this, the notion of transfer of contingent liabilities to the state is emerging as a common feature of CCS regulation. ${ }^{161}$ This reflects a fundamental misalignment of risk: in light both of the mutability of corporate operators and the limits on levels of financial assurance (including insurance) that can realistically be negotiated in the market. So a key question relates to the terms on which risk transfer takes place. ${ }^{162}$ For instance, in Australia, liability passes by operation of law to the Commonwealth government (for storage offshore) once at least five years have passed post-closure, provided that the minister is satisfied that no significant risks are posed, and subject to a 15year closure assurance period. Liability extends to 'any' liability, seemingly including even liabilities under the common law (and it is expressly provided that the Commonwealth is also liable where the holder ceases to exist). This contrasts with approaches adopted in the states of Victoria and Queensland (responsible for CCS licensing inland), under which licensed operators may retain liability exposure for an indefinite period. ${ }^{163}$ The Commonwealth measure is arguably the more realistic, especially the longer that time elapses and given the above mutability of commercial entities.

Similarly, EU arrangements set out criteria which include the passage of a minimum post-closure period (which the authority may waive) of 20 years, the operator meeting financial obligations (requiring contribution to a financial mechanism to pay the authority's post-transfer costs), and the authority being satisfied that all available evidence indicates complete and permanent containment. ${ }^{164}$ The approach, on the face of it a pragmatic compromise, seems to ride two horses in different directions: once approved, imposing effective long-term responsibility on the state, ${ }^{165}$ though also allowing authorities with higher risk aversion to seek to avoid transfer risks, by adopting perhaps a zero-risk threshold, a notion elsewhere in EU jurisprudence expressly rejected for application of the precautionary principle. ${ }^{166}$ However, a blanket refusal is likely to be met with administrative law challenge, and perhaps of greater practical significance an increased likelihood of corporate avoidance techniques (such as reduced self-reporting of problems). Collateral impacts on investor confidence in CCS within that jurisdiction might also follow, and so, as projects move towards the closure phase, the expectation must be that indefinite state liability should be anticipated as the likely outcome.

Exclusion of liability under the EU's transfer arrangements may nevertheless be disapplied in the event of operator fault. This notion is expressed in extremely broad terms: including wilful deceit, concealment of relevant information, failure to exercise due diligence,

160 Dir 2009/31/EC (n 24) contains general provisions including those for selection of storage sites, including exploration permits: arts 4, 5; storage permits, arts 6-11; and operations including closure and post-closure, including monitoring: arts 12-20.

161 IEA (n 1) 91-105.

162 Including as to the need for delay in transfer eg reflecting outstanding issues relating to earlier incidents.

163 M Gibbs, 'The Regulation of Geological Storage of Greenhouse Gases in Australia' in Havercroft et al (n 7) 167-70; also A Warburton, J Grove, S Then and K Geddes, 'Geosequestration Law in Australia' in T Bodyhandy and P Christoff (eds), Climate Law in Australia (Federation Press 2007); though in each state statutory ownership of stored gases appears to become state property, suggesting that the state is likely to be first defendant in any third-party action.

164 Dir 2009/31/EC (n 24) art 18(1).

165 Ibid, applicable to obligations under each of the CCS, Environmental Liability and ETS directives; although liability transfer would not apply to other regimes under EU law (such as integrated pollution prevention and control) or domestic law (such as statutory nuisance).

166 Case T-13/99 Pfizer Animal Health SA v Council of EU [2002] ECR II-3305. 
negligence, or what is termed deficient data, in which event there appears to be a duty to recover post-transfer costs thereby incurred. ${ }^{167}$ It may be envisaged that this unusual formulation regarding fault will create uncertainty, especially in the early period following transfer, where the notion of being 'at risk' will be a more realistic possibility. But in the postoperational phases of most economic activities, given a strong scientific research base, circumstances in which liability can arise can be expected thenceforth to reduce. Moreover, although the directive's notion of 'all legal obligations' is further constrained by competence limitations (so excluding private law obligations), ${ }^{168}$ where a potential for harm persists, inherent limits apply as to how far a civil liability regime can capture such risks within rules applicable to recognised causes of action (including as to causation, remoteness and limitation of actions); and, in consequence, such losses would be likely to be left where they lie.

In concluding this section, the distinctiveness of CCS risk transfer is further considered by reference to two partly cognate regimes. First, contrasting regulatory responses may be drawn with regard to liability for nuclear accidents, where in an effort to counter uncertainty, both for entities active in the nuclear industry and respecting state concerns for the public good, two main conventions are place. ${ }^{169}$ Despite the lack of a comprehensive regime, ${ }^{170}$ a shared feature is that exposure to liability is, in the first instance, channelled through the operator, with responsibilities thereafter assumed (in effect, guaranteed) by respective states. ${ }^{171}$ Operator liability provisions are circumscribed by reference to harm, ${ }^{172}$ financial limits ${ }^{173}$ and limitation periods, ${ }^{174}$ with flexibility under which insurance or other financial security arrangements for meeting maximum liabilities are reserved to state level. ${ }^{175} \mathrm{UK}$ operator liabilities are limited to a relatively low maximum exposure relative to other states. ${ }^{176}$ Exposure to liability would significantly increase were the 2004 Protocol in force, ${ }^{177}$ affecting both operators and states as

167 Dir 2009/31/EC (n 24) art 18.7.

168 Member states may exclude operators from such liabilities.

169 The first, under the Organization for Economic Cooperation and Development, through the 1960 Paris Convention on Third Party Liability in the Field of Nuclear Energy, 8 EYB 203 (as supplemented by the 1963 Brussels Convention, 2 ILM 685 (with a Protocol in 2004, not yet in force), including most Western European states; the second, under the International Atomic Energy Agency, through the 1963 Vienna Convention on Civil Liability for Nuclear Damage, 2 ILM 727, amended by protocol in 1997, 36 ILM 1462, mostly covering the former Soviet bloc.

170 A blueprint for one is contained in a 2007 Convention on Supplementary Compensation.

171 See eg Paris Convention (n 169) art 6.

172 Ibid art 3(a) includes harm to humans and damage to property.

173 Ibid art 7 (amended Brussels Convention, art 3) establishes tiers of liability and state discretion in setting for operators a minimum requirement (circa $€ 5$ million), up to a much increased set maximum ( $€ 300$ million), reliance for up to half of which might come from a solidarity provision under art 12 .

174 Ibid art 8.

175 Ibid art 10.

176 Nuclear Installations Act 1965, ss 7ff. The UK maximum is $f_{140}$ million (Nuclear Installations (Increase in Operators' Limits of Liability) Order 1994/909. For comparative illustrations from other jurisdictions, see S Tromans, Nuclear Law: The Law Applying to Nuclear Installations and Radioactive Substances in its Historic Context (2nd edn, Hart Publishing 2010) 185-88.

177 Resistance to the Protocol reflects eg its significant enhancement in the definition of harm, extending to economic loss arising from personal or property damage; and, in the event of impairment of the (wider) environment, costs both of reinstatement and representing loss of income deriving from a direct economic interest in any use or enjoyment of the environment (cf exclusions from the Environmental Liability and CCS directives). 
contracting parties. ${ }^{178}$ Making allowances therefore for uncertain (but potentially vast) exposures to liability, and the consequent problems in arriving at risk evaluations, these limited regimes reflect an awkward balancing as between (especially post-Chernobyl) concerns at the potential scale of harm - still by no means necessarily covered - and the fundamental problem of securing adequate levels of financial security, particularly through private insurance. ${ }^{179}$

A second, more apposite example of a broadly comparable measure, depending on how long-term risks are viewed, may be that contained in a feature of the UK's contaminated land regime, which applies liability for remediation, ${ }^{180}$ expressly extending to past contamination otherwise lying beyond the reach of modern pollution control regimes. The legislation acknowledges that there may no longer be an 'appropriate person' available for service of a remediation notice. ${ }^{181}$ To counter the high mortality of corporate entities over time, in certain circumstances liability may attach to a successor company, though here a narrow judicial interpretation has had the effect of absolving a successor from statutory liability following privatisation. ${ }^{182}$ Moreover, a still more marked contrast between the regimes may be drawn, for, in relation to contaminated land, even in the face of the above problems of attribution no liability is placed upon state agencies, ${ }^{183}$ and under UK law the authority has a power (rather than a duty) to carry out remediation works and recover reasonable costs. ${ }^{184}$ This raises questions as to that regime's general effectiveness, ${ }^{185}$ although with resource pressures on regulators, the costs burden can be partially shifted from the public to the private domain under the more negotiated processes of development planning, thereby avoiding any more coercive remediation regime. ${ }^{186}$

Liability in CCS post-operational phases, by analogy with the above, is limited by both institutional and temporal constraints. The issue of survival of the operator as a legal entity is especially problematic, and here the CCS directive appears to have made a virtue of necessity, with state long-term responsibility arguably representing a notion of the public good; though it might seem that at the heart of the transfer solution lie public-private partnership arrangements that privatise potential profits whilst socialising attendant longerterm risks. To some degree, exposure from the authority's perspective will be mitigated by a statutory financial mechanism, compensating for monitoring costs over a 30-year period, with potential for a further discretionary figure to cover costs to ensure permanent containment. ${ }^{187}$ Even here, such a mechanism can only deliver what the financial and

178 To a maximum of $€ 1500$ million, respectively made up by an operator obligation of $€ 700$ million (nondiscretionary, the state to indemnify if insurance is not available to satisfy claims up to that figure) and total contracting party obligations up to $€ 800$ million; see M Hintergger, 'The Paris Convention 2004: A New Liability System for Europe' [2004] 3 Environmental Liability 116.

179 See generally J C Dow, Nuclear Energy and Insurance (Witherby 1989)

180 Environmental Protection Act 1990, pt IIA.

181 Ibid ss $78 \mathrm{H}, 78 \mathrm{~N}$ : a further caveat, not directly analogous here, is where such person would suffer hardship if required to contribute to remediation.

182 R (Application of National Grid, formerly Transco) v Environment Agency [2008] Env LR 4.

183 The original proposal for the Environmental Liability Directive would have placed obligations on member states as a last resort.

184 Environmental Protection Act 1990, ss 78N, 78P.

185 See B Pontin and C Willmore, 'Displacing Remedies from Environmental to Planning Law: the Enforcement of Contaminated Land Regulation in Britain' (2006) 6 Yearbook of European Environmental Law 97.

186 S Vaughan, 'The Contaminated Land Regime: Still Suitable for Use?’ [2010] JPL 142, 149-53.

187 Dir 2009/31/EC (n 24) art 18.1; these are barely estimable, though the European Commission may adopt indicative guidelines under art 8.2. 
insurance markets are willing to bear, ${ }^{188}$ and there is a regrettable lack of further explicit linkage to a more extensive establishment of trust funds from revenues generated during operational phases. ${ }^{189}$ The inadequacy of private cover would be a considerable brake on the potential effectiveness of any of the above arrangements, and so in respect of longterm risk CCS depends ultimately on government willingness to act as guarantor.

\section{Conclusions}

Accordingly, there is a now widespread acceptance of a need to pursue the potential of CCS as an integral part of the search for solutions to the challenge of cutting carbon emissions. At the heart of societal expectations of CCS, however, lies a fundamental dilemma: as between the logical inferences to be drawn from climate science (especially concerning the imperative of reducing fossil fuel use and, in particular, coal) and the vulnerabilities of lowcarbon strategies to the 'business as usual' effect (in the event that CCS proves unable to deliver upon expectations). ${ }^{190}$ The problem of lock-in was referred to above, whereby dangerous levels of emissions continue, supported by an over-dependency upon the regulation of 'inherently anti-ecological activities',191 in the hope that CCS technology eventually proves adequate to the task of compensating failures in mitigating emissions.

Meaningful engagement with dilemmas over reducing carbon intensity for activities across a developed economy such as that of the UK ultimately depends on two key factors: first, reducing uncertainties affecting low-carbon investment (including reinventing the need to choose winners in a field that remains market-driven); and, secondly, adopting multilevel, pluralistic approaches to the development of policies and laws that seek to achieve the reduction of greenhouse gas emissions. The previous discussion from the perspective of governance was informed by the challenges that arise. It is now clear that any success in tackling climate change, as part of a wider pursuit of sustainability, will require a further blurring, as identified above, of distinctions between the public and the private domains. This is especially the case as ongoing efforts must be pursued within an energy context in which the state explores new roles and relationships with an industry which still must operate in accord with the dictates of the marketplace.

It has been argued that, without an appropriate and coherent regulatory framework, then, the complex challenges posed by CCS across each of its developmental, operational and post-operational phases cannot be addressed. In particular, regulatory approaches need to be adopted with a view to mitigating the uncertainties identified here. The field continues to be marked by wide-ranging technological, economic and investment uncertainties; as well as uncertainties as to the extent of respective health and environmental risks, including into the long term in the event of leakage from storage sites, with the further potential consequence of undermining emissions reduction objectives. In discussing instrumental responses it was further seen that complex tensions can arise, especially where different

188 Cf UK insurers subscribe to a pool operated under the agency of a company limited by guarantee for this purpose, Nuclear Risk Insurers Ltd, with insurers severally liable for respective shares of insured risks; see further, Tromans (n 176) 217-26.

189 A common feature adopted initially for pilot project sites in the US, typically in those states with extensive extraction histories such as North Dakota, Montana; also adopted in Wyoming, Louisiana: see J J Snyder, 'Obstacles to Regulation of Carbon Capture and Sequestration by US States: Can They Be Overcome?' in Havercroft et al (n 7) 204.

190 See eg J Hansen, Storms of My Grandchildren: The Truth about the Coming Climate Catastrophe and Our Last Chance to Save Humanity (Bloomsbury 2011), 193-94.

191 R White, Crimes against Nature: Environmental Criminology and Ecological Justice (Willan Publishing 2008) 232; see further R Field, 'Risk and Justice: Capitalist Production and the Environment' in D Farber (ed), The Struggle for Ecological Democracy: Environmental Justice Movements in the United States (Guilford Press, 1998). 
legal regimes, with varied regulatory purposes, must accommodate one another. And yet in the wider analysis of regulatory prospects, lessons could likewise be drawn from experience in applying regulatory approaches to other environmental problems.

In light of the CCS directive alongside other interventions, it has been seen that a policy dynamic is emerging within the EU in the fields of climate change and now also energy, which by virtue of what has been termed institutional lock-in will increasingly influence member state actions, in compliance with legally binding emissions reductions commitments. There is a growing range of regulatory strategies in place, including under command-and-control and economic mechanisms (such as ETS), establishing a framework under which the development and control of carbon sequestration may take place. For the UK, with government seeking to have contracted commitments to currently two pilot projects in place by 2015, looking thence toward delivering CCS as a competitive element within the energy portfolio, emerging strategy will need to identify anticipated risks and costs scenarios as a precondition to securing realistic infrastructure investment across the sector through the 2020 s and beyond. ${ }^{192}$ Should CCS become established, then from a storage perspective, it will be essential to pursue regulatory strategies that address identified uncertainties, especially in respect of the new risks that arise, such as harm from off-site migration into ambient air or onto surface land, and leakage to adjacent sub-surface areas. Resulting challenges directly engage with questions of regulatory capability and in this key respect the contribution of law continues to be fundamental.

192 See the latest report of the Committee on Climate Change, Meeting Carbon Budgets, Fifth Progress Report to Parliament (London: Stationery Office, June 2013), 'Commercialisation of CCS' 94-98. 
